\title{
Splitting of the distal median nerve
}

\author{
W.L. Smith ${ }^{1}$, Ł. Olewnik², J. Iwanaga ${ }^{3-5}$, A.S. Dumont ${ }^{3}$, R.S. Tubbs ${ }^{3,4,6-10}$ \\ ${ }^{1}$ Tulane University School of Medicine, New Orleans, LA, United States \\ ${ }^{2}$ Department of Anatomical Dissection and Donation, Medical University of Lodz, Poland \\ ${ }^{3}$ Department of Neurosurgery, Tulane University School of Medicine, New Orleans, LA, United States \\ ${ }^{4}$ Department of Neurology, Tulane Centre for Clinical Neurosciences, Tulane University School of Medicine, \\ New Orleans, LA, United States \\ ${ }^{5}$ Division of Gross and Clinical Anatomy, Department of Anatomy, Kurume University School of Medicine, \\ Kurume, Fukuoka, Japan \\ ${ }^{6}$ Department of Structural and Cellular Biology, Tulane University School of Medicine, New Orleans, LA, United States \\ 'Department of Neurosurgery and Ochsner Neuroscience Institute, Ochsner Health System, \\ New Orleans, LA, United States \\ ${ }^{8}$ Department of Anatomical Sciences, St. George's University, St. George's, Grenada, West Indies \\ ${ }^{9}$ Department of Surgery, Tulane Centre for Clinical Neurosciences, Tulane University School of Medicine, \\ New Orleans, LA, United States \\ ${ }^{10}$ University of Queensland, Brisbane, Australia
}

[Received: 12 September 2021; Accepted: 29 October 2021; Early publication date: 26 November 2021]

\begin{abstract}
Variations of the nerves of the forearm can lead to unexpected clinical findings during physical examination. Additionally, surgery in this region might encounter and potentially damage the nerve in such patients. Here, we present a case of a high split of the median nerve and discuss the findings of the case as well as review salient reports in the literature. Knowledge of such a variation can be important in patient diagnosis and treatment. (Folia Morphol 2023; 82, 1: 190-193)
\end{abstract}

Key words: anatomy, variation, upper limb, hand, forearm

\section{INTRODUCTION}

The median nerve travels through the anterior compartments of the arm and forearm and is often involved in pathological condition, e.g., carpal tunnel syndrome. Variations of the median nerve in the carpal tunnel have been documented and such variations increase the risk of injury during treatment. The median nerve in the forearm can varies: it can pierce the humeral head of the pronator teres or pass deep to the two heads; it may split with the ulnar artery, palmaris longus, flexor pollicis longus, or variant muscle tendons traversing it; and it may travel on the superficial surface of the flexor digitorum superficialis (FDS) instead of deep to it $[1-3,5-8]$.
Here, we present a case in which the median nerve split in the forearm through the FDS.

\section{CASE REPORT}

During the routine dissection of a 42-year-old at death female cadaver, an unusual variant of the median nerve was observed in the right upper limb. At $10.5 \mathrm{~cm}$ distal to the medial epicondyle, the nerve forked into two unequal branches. The smaller medial branch ( $3 \mathrm{~mm}$ diameter) travelled $6.5 \mathrm{~cm}$ distally to enter the musculotendinous junction of the FDS to the fourth digit, entered the carpal tunnel superficial to all of the long flexor tendons to then terminate as the digital nerve to the lateral side of the fourth digit (Fig. 1). No additional branches were seen from

Address for correspondence: J. Iwanaga, DDS, PhD, Department of Neurosurgery, Tulane Centre for Clinical Neurosciences, Tulane University School of Medicine, 131 S. Robertson St. Suite 1300, New Orleans, LA 70112, United States, tel: 5049885565, fax: 5049885793, e-mail: iwanagajoeca@gmail.com This article is available in open access under Creative Common Attribution-Non-Commercial-No Derivatives 4.0 International (CC BY-NC-ND 4.0) license, allowing to download articles and share them with others as long as they credit the authors and the publisher, but without permission to change them in any way or use them commercially. 




Figure 1. Lateral view of the forearm and hand of the specimen described herein. The lateral edge of the flexor digitorum superficialis is reflected up. The pre-split part of the median nerve is seen at the yellow arrow and the medial and lateral branches seen at the blue and black arrows, respectively.

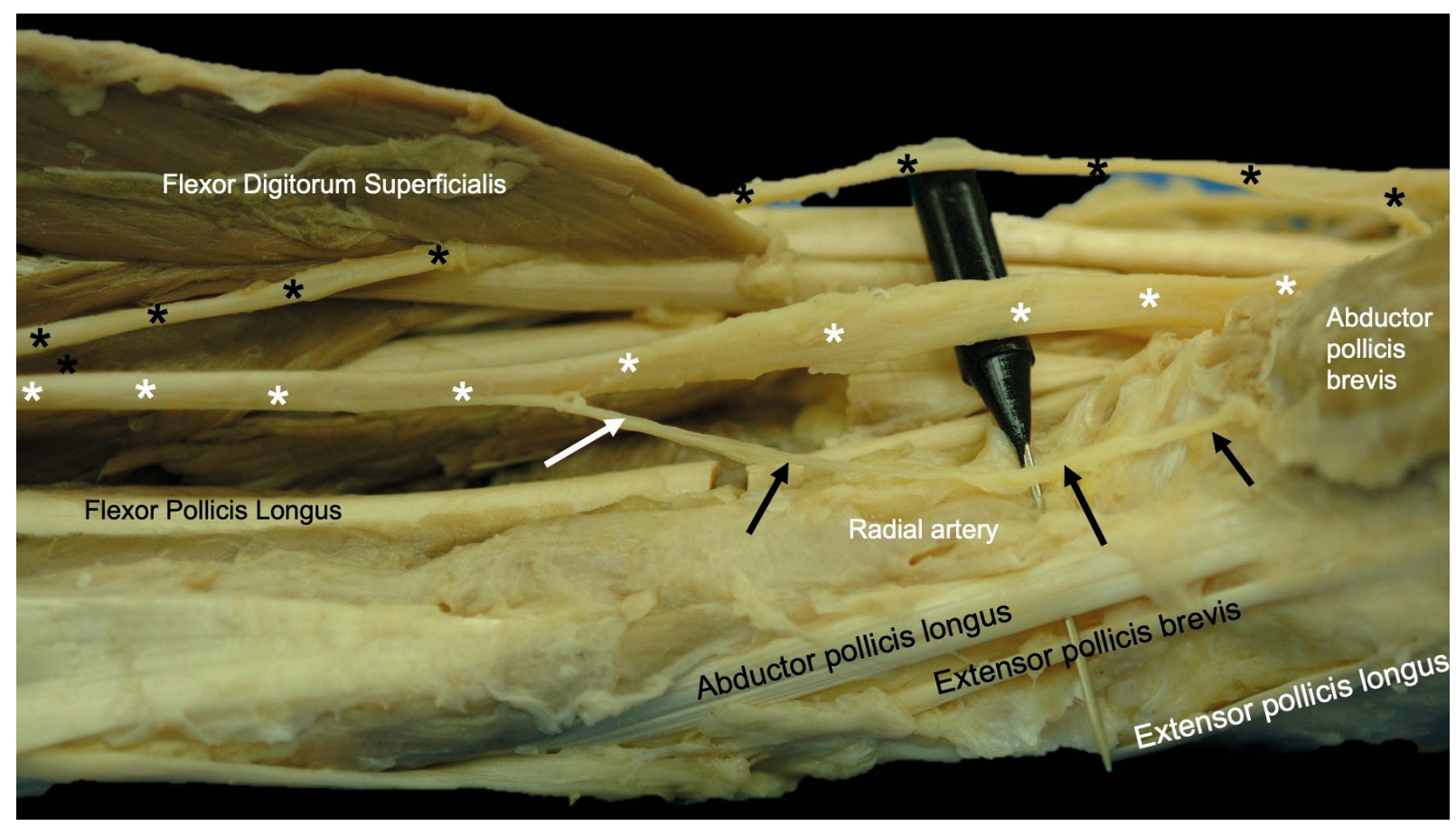

Figure 2. Zoomed in view of Figure 1. Note the medial (black asterisk) and lateral (white asterisk) branches of the split median nerve. The arrows note the palmar cutaneous branch of the nerve arising from the lateral branch.

this branch. The larger lateral branch $(5 \mathrm{~mm}$ diameter) continued from the split distally between the FDS and flexor digitorum profundus and about the same level as the medial branch pierced the FDS; it gave rise to the palmar cutaneous branch (Fig. 2). This branch continued distally through the carpal tunnel just lateral to the medial branch of the split median nerve. In the hand, this part of the median nerve gave rise to the recurrent branch, branches to the first and second lumbricals, and terminated as digital nerve branches to the lateral three digits. No communicating branches were identified between the medial and lateral branches of the split median nerve in the forearm or hand. The contralateral median nerve was found to have a typical pathway with no splitting through the FDS. 


\section{DISCUSSION}

Incidence of a split (bifid, bipartite, bifurcated) just proximal to the flexor retinaculum is reported $2.8 \%$ and is usually coexistent with a persistent and often enlarged median artery although this was not seen in our specimen $[10,15,20]$. More proximal splits or "high" divisions, such as presented here, that occur more proximal to the wrist have been described but this is much more uncommon $[13,14,17,18,21]$. These high divisions can typically be separated into branching with no associated muscle or artery or branching with an associated lumbrical muscle between the branches $[12,16]$. A handful of cases of median nerves being split by a tendon of the FDS have been reported $[4,9,12,24]$. A case has been reported where the median nerve in the proximal forearm was split by a band between the FDS and flexor pollicis longus, but reunited proximal to the flexor retinaculum was identified [24]. Kadar et al. [12] identified two cases in which the median nerve was split into medial division and lateral divisions by the FDS. In one case, the medial division terminated as the third interspace common digital nerve and was separated by the tendon of palmaris longus and FDS tendon to the fourth finger. In the other case, both divisions provided fibres to the third interspace common digital nerve. In both of these cases no persistent median artery was present [12].

In a similar case to ours, Winkleman and Spinner [23] identified a median nerve that split $9.5 \mathrm{~cm}$ distal to the medial epicondyle and travelled separately into the carpal tunnel accompanied by a persistent median artery. A communicating branch from the main median nerve rejoined the split portions distal to the flexor retinaculum. In another case, Tubbs and Salter [22] identified a median nerve that split $6 \mathrm{~cm}$ distal to the medial epicondyle. The medial and lateral branches of the split median nerve travelled separately through the carpal tunnel and communicated in the palm. However, the present case did not have a persistent median artery or a communicating branch between to the parts of the split. In both cases, however, the medial branch of the split median nerves penetrated the FDS.

\section{CONCLUSIONS}

In case of unusual presentations of median nerve entrapment, the clinician should include in their differential diagnosis that the patient has a proximally split nerve. These variations might cause nerve com- pression with contraction of the FDS and produce pain suggestive of carpal tunnel syndrome or other entrapment syndromes of the forearm [12, 19]. As found in our case, signs or symptoms of median nerve compression where sensation is normal in the palm but compromised along the lateral aspect of the fourth digit, the lateral branch of the split median nerve might be considered to be compressed by the FDS proximal to the wrist. Lastly, surgery of the anterior forearm could potentially injure such a split median nerve, especially the medial branch of the split as it traverses the FDS and is in a more superficial position in the distal forearm more proximally.

\section{Acknowledgements}

The authors sincerely thank those who donated their bodies to science so that anatomical research could be performed. Results from such research can potentially increase mankind's overall knowledge that can then improve patient care. Therefore, these donors and their families deserve our highest gratitude [11].

\section{Conflict of interest: None declared}

\section{REFERENCES}

1. Amadio PC. Bifid median nerve with a double compartment within the transverse carpal canal. J Hand Surg Am. 1987; 12(3): 366-368, doi: 10.1016/s03635023(87)80005-9, indexed in Pubmed: 3584882.

2. Anson B. Morris' Human Anatomy. 12th Ed. McGraw-Hill, Blakiston Division 1966.

3. Artico M, De Santis S, Cavallotti D, et al. Anatomical variations of the ulnar and median nerves in the upper limb. Ital J Anat Embryol. 2000; 105(3): 189-200, indexed in Pubmed: 11103856.

4. Baruch A, Hass A. Anomaly of the median nerve. J Hand Surg Am. 1977; 2(4): 331-332, doi: 10.1016/s03635023(77)80143-3, indexed in Pubmed: 893990.

5. Bergman RA, Afifi AK, Saadeh FA. Compendium of human anatomic variation. Urban \& Schwarzenberg, Baltimore 1988.

6. Cavallo AV, Slattery PG, Barton RJ. Endoscopic carpal tunnel release and congenital anomalies of the median nerve. Hand Surg. 2003; 8(2): 265-270, doi: 10.1142/ s0218810403001753, indexed in Pubmed: 15002109.

7. Crandall RC, Hamel AL. Bipartite median nerve at the wrist. Report of a case. J Bone Joint Surg Am. 1979; 61(2): 311, doi: 10.2106/00004623-197961020-00034.

8. Eiken O, Carstam N, Eddeland A. Anomalous distal branching of the median nerve. Case reports. Scand J Plast Reconstr Surg. 1971; 5(2): 149-152, doi: 10.3109/02844317109042956, indexed in Pubmed: 5136058.

9. Fernandez-Garcia S, Pi-Folguera J, Estallo-Matino F. Bifid median nerve compression due to a musculotendinous 
anomaly of FDS to the middle finger. J Hand Surg. 2016; 19(5): 616-617, doi: 10.1016/0266-7681(94)90128-7.

10. Gutowski KA, Olivier WA, Mehrara BJ, et al. Arteriovenous malformation of a persistent median artery with a bifurcated median nerve. Plast Reconstr Surg. 2000; 106(6): 1336-1339, doi: 10.1097/00006534-200011000-00016, indexed in Pubmed: 11083565.

11. Iwanaga J, Singh V, Takeda S, et al. Acknowledging the use of human cadaveric tissues in research papers: Recommendations from anatomical journal editors. Clin Anat. 2021; 34(1): 2-4, doi: 10.1002/ca.23671, indexed in Pubmed: 32808702.

12. Kadar IA, Virág TH, Matei IR, et al. High division of the median nerve with unusually high origin of the 3rd space common digital nerve. Injury. 2020; 51 Suppl 4: S96-S102, doi: 10.1016/j.injury.2020.03.024, indexed in Pubmed: 32197831.

13. Kessler I. Unusual distribution of the median nerve at the wrist. A case report. Clin Orthop Relat Res. 1969; 67: 124-126.

14. Kitayama $Y$, Tsukada S, Kurokawa M. High division of the median nerve: unusual anatomical variation. Ann Plast Surg. 1985; 14(1): 74-76, doi: 10.1097/00000637198501000-00013, indexed in Pubmed: 3977243.

15. Król A, Palczak A, Jedrzejewski KS. Split median nerve. A report of two cases. Folia Morphol. 2005; 64(4): 341-344, indexed in Pubmed: 16425164.

16. Lanz U. Anatomical variations of the median nerve in the carpal tunnel. J Hand Surg Am. 1977; 2(1): 44-53, doi: 10.1016/ s0363-5023(77)80009-9, indexed in Pubmed: 839054.
17. Matini K. Abnormal distribution of the median nerve at the wrist and forearm. Plast Reconstr Surg. 1983; 71(5): 711-713, doi: 10.1097/00006534-198305000-00025, indexed in Pubmed: 6836068.

18. Moneim M. Unusually high division of the median nerve. J Hand Surg. 1982; 7(1): 13-14, doi: 10.1016/s03635023(82)80005-1.

19. Orellana-Donoso M, Valenzuela-Fuenzalida J, Gold-Semmler M, et al. Neural entrapments associated with musculoskeletal anatomical variations of the upper limb: Literature review. Transl Res Anat. 2021; 22: 100094, doi: 10.1016/j.tria.2020.100094.

20. Propeck T, Quinn TJ, Jacobson JA, et al. Sonography and MR imaging of bifid median nerve with anatomic and histologic correlation. AJR Am J Roentgenol. 2000; 175(6): 1721-1725, doi: 10.2214/ajr.175.6.1751721, indexed in Pubmed: 11090410.

21. Thompson I. Anomaly of median nerve and flexor digitorum sublimis muscle. The Anatomical Record. 1922; 23(7): 375-379, doi: 10.1002/ar.1090230706.

22. Tubbs RS, Salter EG. A rare finding of the median nerve in the forearm. Clin Anat. 2006; 19(8): 704-705, doi: 10.1002/ca.20310, indexed in Pubmed: 16838289.

23. Winkelman NZ, Spinner M. A variant high sensory branch of the median nerve to the third web space. Bull Hosp Joint Dis. 1973; 34(2): 161-166.

24. Won HS, Oh CS, Chung IH. A split and conjoined median nerve in the forearm. Anat Sci Int. 2010; 85(2): 115-117, doi: 10.1007/s12565-009-0040-3, indexed in Pubmed: 19337785. 